Browne, F. J., and Browne, J. C. McClure (1955). Postgraduate Obstetrics and Gynaecology, 2nd ed., p. 236. Butterworth, London.

Burton-Brown, J. R. C. (1949). J. Obstet. Gynaec. Brit. Emp., 56, 847 .

Davis, M. E., and Boynton, M. W. (1942). Amer. J. Obstet. Gynec., 43, 775 .

Dewhurst, C. J. (1952). Lancet, 2, 746.

Dutton, W. A. C. (1958). J. Obstet. Gynaec. Brit. Emp., 65, 315. Elwin, P. M. (1960). Brit. med. J., 1, 1569.

Fraser, A. C., and Tatford, E. P. W. (1961). Lancet, 2, 126.

Greenhill, J. P. (1960). Obstetrics, 12th ed., p. 307. Saunders, Philadelphia and London.

Kimbell, N. (1958). Brit. med. J., 1, 203.

Leff, M. (1929). Amer. J. Obstet. Gynec., 18, 868.
Lloyd, H. N. (1949). Proc. roy. Soc. Med., 42, 1.

Martin, J. D., and Dumoulin, J. G. (1953). Brit. med. J., 1, 643. Ministry of Health (1960). Report of Confidential Enquiries into Maternal Deaths in England and Wales, 1955-7. H.M.S.O., London.

Moir, J. Chassar (1956). Munro Kerr's Operative Obstetrics, 6th ed., p. 48. Baillière, Tindall and Cox, London.

Morris, W. I. C. (1959). British Obstetric and Gynaecological Practice, edited by Sir Eardley Holland and Aleck Bourne, 2nd ed., p. 809.

Nixon, W. C. W. (1955). W. Afr. med. J., 4, 52

Picton, F. C. R. (1951). J. Obstet. Gynaec. Brit. Emp., 58, 764.

Stabler, $\mathbf{F}$. (1957). Brit. med. J., 2, 217.

Williams, J. Whitridge (1924). Obstetrics, 5th ed., p. 336. Appleton, New York and London.

\title{
SIGNIFICANCE OF SITE OF PLACENTAL ATTACHMENT IN UTERUS
}

BY

\author{
R. T. BOOTH, M.B., B.S., M.R.C.o.G. CARL wOOD, M.B., B.S., F.R.C.S., M.R.C.o.G. \\ R. W. BEARD, M.B., B.Ch., D.Obst.R.C.O.G. \\ J. R. M. GIBSON, M.B., B.S., D.Obst.R.C.O.G. \\ AND
}

JOHN H. M. PINKERTON, M.D., F.R.C.O.G.

From the Institute of Obstetrics and Gynaecology, Queen Charlotte's Hospital, London

Using soft-tissue radiography to determine the situation of the placenta, Stevenson (1949) and Whitehead (1953) found that the attachment of the placenta at one or other pole of the uterus may cause the foetus to lie transversely. Stevenson (1950) also stated that in breech pregnancies at or near term the placenta was always attached to the cornuo-fundal region of the uterus, and Fell (1956) confirmed that this placental site was more common in breech presentation. Torpin and Faulkner (1957) reported that occipito-posterior positions were more frequent when the placenta was anterior $(47.4 \%)$ than when the placenta was posterior (21.2\%). Evidence was accumulated by Ranney (1956) that retained placentae were more common when the placenta was attached to the cornual region of the uterus, and Kushnirskaya and Ivanova (1958) found a high postpartum haemorrhage rate if the placenta was large or was attached to the lower uterine segment.

An interesting theory concerning the aetiology of pre-eclamptic toxaemia was proposed by Bieniarz (1959) on the basis of his finding that toxaemia was most frequent when the placenta was attached high in the uterus. He described different vascular patterns of the pregnant uterus, the utero-placental circulation draining mainly through the ovarian veins in high-situated placentae and mainly through the uterine veins in low-situated placentae. These observations supported his hypothesis that a high draining of the utero-placental circulation might cause a pathological redistribution of blood in the renal and visceral circulation, resulting in pre-eclamptic toxaemia.

Csapo (1956) proposed a theory that the placenta gives its progesterone locally to the neighbouring myometrium rather than indirectly through the systemic circulation. The result of this would be a progesterone concentration gradient in the myometrium with a peak at the placental implantation site. Csapo (1961) has demonstrated that progesterone prevents the propagation of the excitation wave in uterine muscle and has produced evidence that this hormone is a key substance in the maintenance of pregnancy because of its blocking action on myometrial function. He suggested that if the placenta were attached at or below the middle of the uterus, then as term approached the fundus would recover first from the progesterone block and a downward gradient of uterine activity from the fundus to the cervix would develop. If the placenta were located high, the lower uterine segment would recover first from the progesterone block and, as the activity gradient of the uterus would point in the wrong direction, prolonged labour might occur.

Following a suggestion by Csapo (1960, personal communication), it was decided to determine the placental site in 200 patients and attempt to correlate this information with the duration of the patient's labour. Other obstetrical features of the patients were also examined to see if they were affected by the location of the placenta.

\section{Material and Methods}

There were 150 primigravidae and 50 multigravidae in the study. The selection of cases was determined by the presence of adequate anaesthesia or analgesia.

The placental site was determined by performing manual exploration of the uterus immediately after delivery of the foetus. In a small number of patients the placental site could not be determined because the placenta had already separated or was in the process of separating at the time of the examination. The position of the placenta was described in both the longitudinal (fundal, upper, and lower segment) and transverse (anterior, posterior, and lateral) planes of the uterus (see Table I). No complications resulted from this examination.

TABLE I.-Site of Placental Attachment in 150 Primigravidae

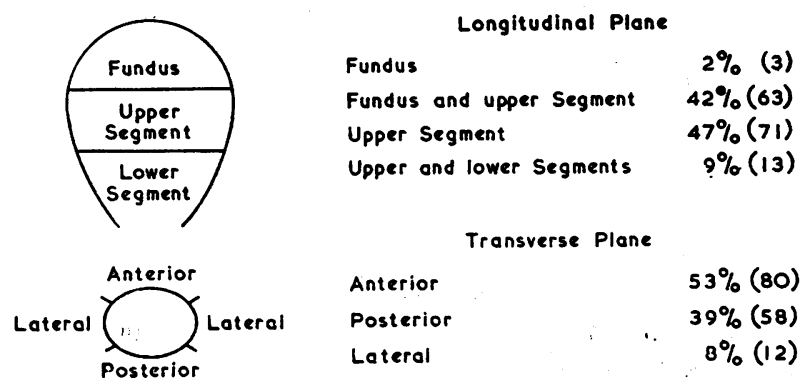


A number of patients in the series had been radiographed for a variety of obstetric indications; in 24 the placental site could be defined, and these provided an opportunity to compare the accuracy of $x$-ray placentography with that of manual exploration of the uterus.

\section{Results}

Although the most usual site of placental attachment in the 150 primigravidae was anterior or posterior in the upper uterine segment (Table I), variations from this were common. In many patients the placenta encroached on to the uterine fundus $(42 \%)$ but a complete fundal attachment of the placenta was rare (2\%). A demarcation between the upper and lower uterine segment was easily determined during manual exploration; it was found that the placental attachment extended into the lower uterine segment in 13 cases $(9 \%)$. The placenta was attached to the fundus in only $20 \%(10 / 50)$ of multigravidae as compared with $44 \%$ $(66 / 150)$ of primigravidae; this difference is highly significant $\left(\chi^{2}=9.1, \mathrm{P}<0.01\right)$. Otherwise there was no significant variation with parity in the placental site.

The relationship between the duration of labour and the location of the placenta was analysed in primigravidae with the vertex presenting. In three patients with a completely fundal placenta labour lasted $2 \frac{1}{2}, 14$, and 22 hours. In order to examine further the effect of the longitudinal situation of the placenta on the length of labour, patients with the placenta attached to both the fundus and the upper segment were matched against those with the placenta only in the upper segment (Table II) ; it was found that the duration of labour in

TABLE II.-Placental Site and the Duration of Labour in 135

\begin{tabular}{|c|c|c|c|c|c|}
\hline \multicolumn{6}{|c|}{ Primigravidae with Vertex Presentation } \\
\hline \multirow{2}{*}{ Placental Site } & \multirow{2}{*}{$\begin{array}{l}\text { No. of } \\
\text { Cases }\end{array}$} & \multicolumn{4}{|c|}{ Duration of Labour in Hours } \\
\hline & & $0-8$ & $9-16$ & $17-24$ & $>24$ \\
\hline $\begin{array}{l}\text { Fundal and upper } \\
\text { segment } \\
\text { Upper segment } \ldots\end{array}$ & $\begin{array}{l}60 \\
75\end{array}$ & $\begin{array}{l}26 \cdot 6 \% \\
30 \cdot 6 \%\end{array}$ & $\begin{array}{l}46.6 \% \\
47.9 \%\end{array}$ & $\begin{array}{l}11 \cdot 6 \% \\
10 \cdot 6 \%\end{array}$ & $\begin{array}{l}15 \% \\
10.6 \%\end{array}$ \\
\hline
\end{tabular}

The incidence of pre-eclampsia was different in the two groups of patients, but the presence of pre-eclampsia did not alter the length of labour in the but the presenc
whole series.

these two groups was similar. The site of the placenta in the transverse uterine plane also had no effect on the duration of labour. In the 50 multigravidae two patients had completely fundal placentae, their labours lasting 2 and 14 hours.

Pre-eclamptic toxaemia (defined as the presence of at least two of the three signs-a blood-pressure of $140 / 90$ $\mathrm{mm} . \mathrm{Hg}$, generalized oedema, and proteinuria) was twice as common when the placenta was attached to the uterine fundus as when it was attached below the fundus (Table III).

TABLE III.-Relationship Between Incidence of Pre-eclamptic Toxaemia and Placental Site in Primigravidae Incidence of Placental Site Pre-eclamptic Toxaemi

Fundal and upper segment $\} \quad$.. $39 \%(26 ; 66)$ Upper segment
and lower segments $\} \quad . . \quad 19 \%(16 / 84)$

The two groups of patients were comparable in age, parity, and duration of pregnancy.

The difference between the percentages is highly significant $\left(x^{2}=7.5\right.$, d.f. $=1, P<0.01$ )

The placenta extended into the lower uterine segment in 13 primigravidae, two of whom had a symptomless retroplacental haemorrhage and one an intrapartum haemorrhage of unknown cause. Post-partum haemor- rhage ( $>20 \mathrm{oz}$; $570 \mathrm{ml}$.) occurred in another 2 of the 13 primigravidae, and five of them lost between 10 and $20 \mathrm{oz}$. (285 and $570 \mathrm{ml}$.) of blood. It is probable that placentae which cannot be diagnosed clinically as praevia, but which extend a short distance into the lower segment, are associated with an increased risk of ante-partum and post-partum haemorrhage.

In 24 patients the placental site could be determined on available $x$-ray films. Agreement between the results thus obtained and the placental location determined by manual exploration of the placenta in 21 of the 24 patients suggested that both techniques were usually reliable (Table IV). Since in two of the three patients

TABLE IV.-Comparison of Soft-tissue X-ray Placentography and Manual Exploration of Uterus in Determining Placental Site

Placental sites similar when determined by $x$-ray and manual exploration

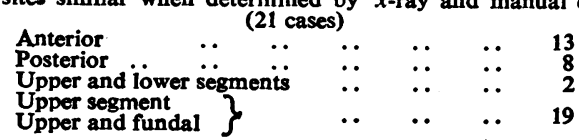

Placental sites different when determinod by $x$-ray and manual exploration

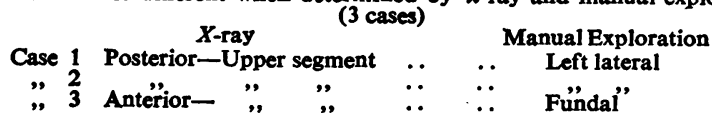

in whom the results differed manual exploration of the uterus revealed lateral placentae, it is possible that softtissue radiography is less accurate in visualizing the placenta in the lateral than in the central part of the uterus.

No relationship between the placental site and the duration of pregnancy or foetal weight was found. In three of five patients who had a manual removal the placenta was attached to the cornual region of the uterus, and in two of the five patients with breech presentation the placenta was cornual.

\section{Discussion}

The findings in this series supported Bieniarz's observation that pre-eclamptic toxaemia was more common when the placenta was attached to the uterine fundus. In addition, the fundal placentae were less common in multigravidae than primigravidae; and Bieniarz, on the basis of a similar observation, suggested that this was one reason why pre-eclamptic toxaemia was less frequent in the multigravida.

The failure to show a relationship between the situation of the placenta and the duration of labour, which is contrary to the impression gained from the first 72 cases (Pinkerton, 1961), does not imply that Csapo's (1956) theory concerning the local action of placental progesterone on the adjacent myometrium is incorrect; for it is possible that the location of a placental myometrial block might have little effect on the duration of labour, or the block might be almost completely removed prior to the onset of labour.

\section{Summary}

The location of the placenta was determined in 200 patients by manual exploration of the uterus immediately after delivery. Extension of the placental attachment into the lower uterine segment occurred in $9 \%$ of cases.

Fundal attachment of the placenta occurred in $44 \%$ of primigravidae and $20 \%$ of multigravidae.

Pre-eclamptic toxaemia was twice as common in patients with the placenta situated in the uterine fundus. 
No relationship between the placental site and the duration of pregnancy or the length of labour was found.

ADDENDUM.-One objection to the present study is that the assessment of the length of labour when the placenta has partially extended on to the uterine fundus may not adequately test Csapo's hypothesis (personal communication, 1961) as he postulates an effect only when the placenta is completely fundal. Nevertheless, there were five completely fundal placentae in the present series, and the length of labour was very short in two of these cases ( 2 and $2 \frac{1}{2}$ hours).

\section{REFERENCES}

Bieniarz, J. (1959). Amer. J. Obstet. Gynec., 78, 385.

Csapo, A. (1956). Amer. J. Anat., 98, 273.

Fell (1961). Ciba Foundation Study Group, No. 9, p. 3.

Fell, M. R. (1956). J. Obstet. Gynaec. Brit. Emp., 63, 760.

Kushnirskaya, E. S., and Ivanova, E. F. (1958). Akush. $i$ Ginek., 34, No. 1 , p. 35

Pinkerton, J. H. M. (1961). Ciba Foundation Study Group, No. 9, p. 82.

Ranney, B. (1956). Amer. J. Obstet. Gynec., 71, 1049.

Stevenson. C. S. (1949). Ibid., 58, 432.

- (1950). Ibid., 60, 41.

Torpin, R., and Faulkner, A. H. (1957). J. Obstet. Gynaec. Brit. Emp., 64, 582.

Whitehead, A. S. (1953). Ibid., 60, 854

\title{
BLOOD GROUPS AND DISEASE: PREVIOUS TRANSFUSION AS A POTENTIAL SOURCE OF ERROR IN BLOOD TYPING
}

\author{
C. A. CLARKE, M.D., F.R.C.P. \\ R. B. MCCONNELL, M.D., M.R.C.P. \\ Department of Medicine, University of Liverpool \\ AND । \\ P. M. SHEPPARD, M.A., D.Phil. \\ Sub-Department of Genetics, University of Liverpool
}

BY

W. T. A. DONOHOE, A.I.M.L.T.

J. H. MARTINDAle, M.B., Ch.B.

Liverpool Royal Infirmary

The frequent use of blood transfusion has introduced into blood-group surveys a potential source of error large enough to give misleading resalts. This applies especially to investigations concerned with disease, and in particular to conditions such as duodenal ulcer where transfusion is commonly undertaken both in medical and in surgical cases.

It has been known for a long time that transfused cells containing antigens which the recipient lacks can be detected serologically, and techniques based on this fact have been used in studying the survival of transfused cells (Mollison, 1962). This is of minor importance in clinical work because it involves only the A and B antigens and the $D$ antigen of the $R h$ system, and patients should never have received blood with these antigens unless they already possessed them. However, an initial error in D grouping, leading to an Rh-negative patient receiving $\mathrm{Rh}$-positive blood, could be perpetuated for a time, since subsequent tests with anti-D would give a positive reaction. In research work involving the $R h$ antigens other than $D$, as well as the MN and other blood groups, previous blood transfusion can lead to a serious misscoring of a patient's own blood groups.

It occurred to one of us (W.T. A. D.) that this potential source of error ought to be considered as an explanation of the statistically highly significant association between duodenal ulcer and $\mathrm{CDe} / \mathrm{CDE}$ found by Buckwalter and Tweed (1962). We were led to this because on collecting blood (for a similar survey) from patients in medical and surgical wards we very soon found that some of them gave a mixed reaction, a proportion of the cells being agglutinated while some remained free. Such reactions found by the unwary or inexperienced could easily be scored as an uncomplicated positive.

We therefore first approached the matter as an in vitro problem, selecting donor blood of such antigenic composition that, theoretically, it could cause an apparent change in the antigens of the recipient; we used $1 \mathrm{ml}$. of the former to $9 \mathrm{ml}$. of the latter-for example, $1 \mathrm{ml}$. of CDe/cDE MM was added to $9 \mathrm{ml}$. of $\mathrm{CDe} / \mathrm{cde} \mathrm{NN}$. Twenty such investigations were made -14 where the $R h$ system alone could have been changed, 4 where the MN only was involved, and 2 where both could have been altered. It was found that the expected conversion always took place ; it was therefore decided to investigate the problem in vivo. The blood of patients who had been transfused was examined repeatedly in order to ascertain: (1) in what percentage of patients those lacking a particular antigen, and transfused with blood containing that antigen, there was a strong enough positive reaction to lead to an error in grouping (assuming that mixed agglutination was not recognized as such); and (2) how long after their transfusion these cells would continue to give a false-positive reaction.

Method.-Blood of patients sent to the laboratory of the Liverpool Royal Infirmary for routine grouping and cross-matching was, if $R h(D)$-positive, tested by us with anti-C, anti-E, anti-c, 2 anti-M, and 2 anti-N sera, and so also was the donor blood cross-matched with it. After the patients had been transfused, blood was taken from them at intervals for a period of a month and tested with the same antisera.

\section{Results}

The results are shown in Table I. It can be seen that in all the 11 patients (out of 12) who received blood containing an antigen which they did not already possess this antigen could be detected after the transfusion and, moreover, as little as 1 pint $(570 \mathrm{ml}$.) was effective.

Even though there were many free cells, there were always sufficient numbers of large agglutinates to lead to the scoring of the test as positive. Furthermore, in every case tested for four weeks after the transfusion these false-positive reactions were still being found.

\section{Discussion}

There are two questions arising out of these results. First, what deviations from the true blood-group frequencies in a series would be caused by different 